\title{
HIGH TEMPERATURE CREEP DAMAGE MECHANISMS IN A DIRECTIONALLY SOLIDIFIED ALLOY: IMPACT OF CRYSTALLOGRAPHY AND ENVIRONMENT
}

\author{
L. Mataveli Suave ${ }^{1,2}$, J. Cormier ${ }^{1}$, P. Villechaise ${ }^{1}$, D. Bertheau ${ }^{1}$, G. Benoit ${ }^{1}$, F. Mauget $^{1}$, G. Cailletaud ${ }^{3}$, L. Marcin ${ }^{2}$ \\ 1 Institut Pprime, CNRS - Université de Poitiers - ENSMA, UPR CNRS 3346, ISAE-ENSMA, BP 40109, 1 avenue Clément Ader, 86961 \\ Futuroscope - Chasseneuil, France \\ 2 SAFRAN CRT, 1 rue Geneviève Aubé, CS80112, 78772, Magny Les Hameaux Cedex, France \\ 3 Centre des Matériaux - Mines Paristech, CNRS UMR 7633, BP 87, F-91003 Evry cedex, France \\ Keywords: Directionally solidified superalloy, Creep, Oxidation, Grain boundaries
}

\begin{abstract}
The damage mechanisms in creep have been investigated in directionally solidified Mar-M200+Hf (DS200 + Hf) alloy at high temperatures. Creep tests were performed along the solidification and transverse directions. These properties have been compared to experiments using single crystalline (SX) specimens have the same chemical composition.

Creep tests were performed at $750{ }^{\circ} \mathrm{C}, 900{ }^{\circ} \mathrm{C}$ and $1100{ }^{\circ} \mathrm{C}$, with a special focus on the intermediate temperature. Experiments both in air or under high vacuum were performed at this temperature, as well as experiments in air with a variation in sample thicknesses. Compared to longitudinal testing and SX experiments, shorter creep lives are systematically observed during transverse creep testing, whatever the testing temperature. This mainly results from a lower creep ductility along the transverse direction, due to an intergranular fracture mode which is assisted by oxidation at $900^{\circ} \mathrm{C}$ and $1100^{\circ} \mathrm{C}$. The variation in creep life anisotropy observed between $750{ }^{\circ} \mathrm{C}$ and $1100{ }^{\circ} \mathrm{C}$ has been analyzed by considering the contribution of oxidation and local (at the grain scale) elastic and plastic behavior anisotropy. In situ monitoring of strain heterogeneities during transverse creep tests performed at $750{ }^{\circ} \mathrm{C} / 800 \mathrm{MPa}$ and at $900{ }^{\circ} \mathrm{C} / 400 \mathrm{MPa}$ shows that cracks develop between grains prone to large creep strains and at high angle boundaries. Moreover, fast oxidation and $\gamma^{\prime}$-rafting seems to be the main factors reducing the creep life anisotropy.
\end{abstract}

\section{Introduction}

Directionally solidified (DS) Ni-based superalloys are widely used for the manufacturing of blades and vanes in aero-engines and industrial gas turbines [1-3]. Despite DS200+Hf (also known as PWA 1422 [4]) being an old alloy developed more than 40 years ago [5], it is still used for the design of modern aero-engines components such as low pressure turbine blades, especially due to its very good castability, allowing sophisticated blade profile shapes and very thin trailing edges to be made. This kind of material consists of nearly $<001>$ columnar grains oriented along the solidification direction and with random secondary orientations. The alloy studied here, DS200+Hf, has a high hafnium content, of about $1.6 \%$, which has been chosen to achieve a better grain boundary strength at high temperature $[1,6]$, improving the durability during service operations [2]. However, due to the complex blade geometries with platforms, shrouds and profile twisting, in addition to the in service thermal gradients, the main loading direction is not always the common crystallographic direction (i.e. the solidification direction). Moreover, due to the casting process, there are significant grain size differences from the root to the tip of the components that may influence the mechanical properties at high temperature, especially along transverse directions. Some grains may also present a misorientation from the perfect $<001>$ crystallographic orientation of up to $10^{\circ}$.

If the mechanical properties along the solidification direction are well characterized for these alloys $[1,2,5,7-10]$, very limited transverse mechanical properties are available in the open literature (especially in creep). In addition, transverse mechanical properties have never been rationalized taking into account the grain size and a large scatter in mechanical properties was observed, probably due to this missing consideration [11-14]. Finally, DS200+Hf is known to have rather poor environmental resistance compared to other DS or conventionally cast superalloys since, this alloy does not form a continuous and dense alumina scale in the oxidation regime $[2,15]$. Within this context, the main objective of this work is to investigate the anisotropy in creep properties of DS200+Hf alloy in a wide temperature range. Special attention will be paid to the contributions of oxidation and crystallography to the damage mechanisms.

\section{Experimental Procedures}

\section{Materials and specimen preparation}

In the present investigation, all DS200+Hf specimens were machined from solution treated DS plates whose dimensions are $110 \times 65 \times 15 \mathrm{~mm}^{3}$ (see Fig. 1). They were solution heat-treated to dissolve as much as possible of the eutectic and to reduce the dendritic segregation obtained after solidification, according to the following sequence: $1210{ }^{\circ} \mathrm{C} / 30 \mathrm{~min}+1225{ }^{\circ} \mathrm{C} / 30 \mathrm{~min}+$ $1240{ }^{\circ} \mathrm{C} / 4 \mathrm{~h}+$ cooling at or greater than $45^{\circ} \mathrm{C} / \mathrm{min}$ until $700^{\circ} \mathrm{C}$ and air quench (AQ). These plates were further heat treated to optimize the $\gamma^{\prime}$ precipitate size and morphology, and hence, the resulting mechanical properties, specifically creep resistance $[9,10,16]$. The aging heat treatment used is 5 hours at $1100{ }^{\circ} \mathrm{C} / \mathrm{AQ}+16$ hours at $870{ }^{\circ} \mathrm{C} / \mathrm{AQ}$.

Mar-M200+Hf single crystalline specimens (identified as SX in the rest of the paper) were machined from bars which were solidified at SAFRAN-Snecma using a standard Bridgman process. These SX bars were mainly solidified along the $<001>$ crystallographic orientation but additional bars were solidified far away from this orientation, using a grain selector and seeds. The average primary dendrite arm spacing was measured to be in the range of 300-350 $\mu \mathrm{m}$. These bars were further heat treated using the above mentioned solution and aging heat treatments used for the DS plates. The exact orientations of all the SX bars tested are shown in Fig. 2. Due to a relatively low primary misorientation, bars $\mathrm{N}$ and $\mathrm{A}$ can be considered as near $<001>$ orientated, while the other two SX bars were selected to be representative of possible grain orientations that can be met when creep testing along transverse direction using DS 
samples. Bar N, with $\mathrm{a} \sim 46$ degrees primary misorientation and a 20 degrees secondary misorientation, was especially chosen to be representative of grains whose primary misorientation with respect to the $<001>$ direction is the largest one in the fine grain areas of plates (see later). One has to notice that these bars and plates were casted using ingots from the same master heat, whose chemical composition is given in Table II.

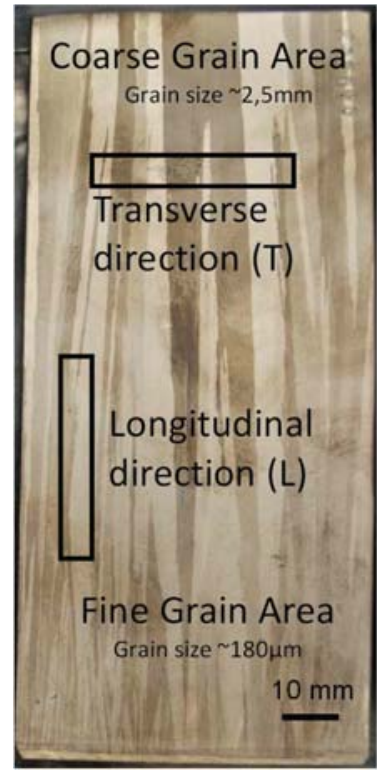

Figure 1. Typical DS200+Hf plate used to machine creep specimens.

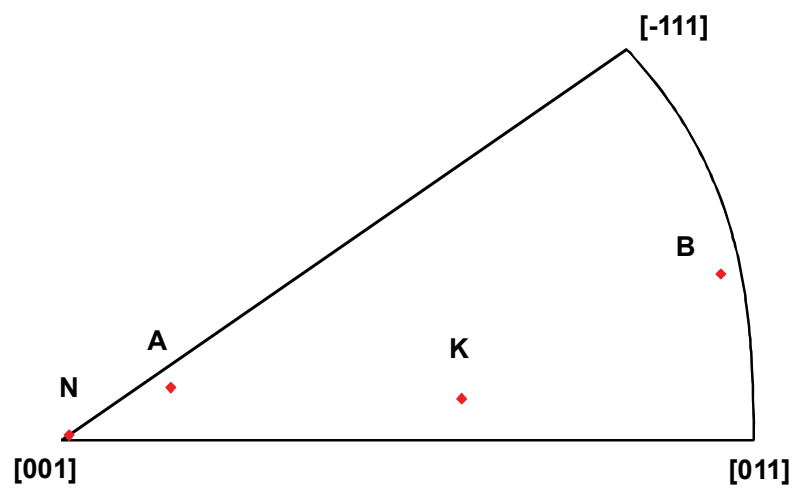

Fig. 2 Orientations of the SX bars tested in the standard stereographic triangle.

Table II. Chemical composition (Wt. \%).

\begin{tabular}{|c|c|c|c|c|c|c|c|c|c|c|c|c|}
\hline Element & Ni & Cr & W & Co & Al & Ti & Nb & Hf & C & B & Zr & Fe \\
\hline Wt. Pct & Bal. & 8.6 & 11.8 & 9.5 & 4.90 & 1.87 & 0.86 & 1.58 & 0.13 & 0.015 & 0.01 & 0.02 \\
\hline
\end{tabular}

Creep and fatigue samples were machined out from the heat treated plates/bars by electron discharge mach ining (EDM) and subsequent turning. Samples were extracted parallel or perpendicular to the solidification direction (L-type or T-type specimens, respectively). T-type specimen were machined both in the fine grain (FG) and coarse grain (CG) areas of the plate (i.e. lower and upper part of the plate presented in Fig. 1). Most of the creep samples had a $42 \mathrm{~mm}$ total length, with a $14 \mathrm{~mm}$ gauge length and a $4 \mathrm{~mm}$ gauge diameter. Additional thin-walled creep samples were further machined from the cylindrical ones. Two parallel flats extending all along the gauge length were machined by EDM to reach thicknesses of $0.5 \mathrm{~mm}, 0.8 \mathrm{~mm}$ and $1.5 \mathrm{~mm}$. This led to prismatic load bearing section of the specimens. For all creep samples, gauge surfaces were carefully low-stress mechanically polished up to a 4000 grade $\mathrm{SiC}$ paper to remove all remaining scratches. The final polishing stage was performed along the gauge length for all kind of samples. All samples dimensions (total length, diameter or thickness and width of the gauge section) were carefully measured using a profilometer before the tests.

Finally, $14 \mathrm{~mm}$ in diameter and $0.9 \mathrm{~mm}$ thick specimens were machined by EDM in both coarse grain (CG) and fine grain (FG) regions of DS plates, as well as in a $<001>$ oriented single crystalline (SX) bar (normal to the specimen surface close to a [001] direction). Each faces of the samples were polished up to a mirror finish. These samples have been used for thermogravimetric (TGA) measurements.

\section{Microstructural characterization}

As observed in Figure 3, showing an EBSD characterization in a plane perpendicular to the solidification direction, the grain size is $\sim 181 \mu \mathrm{m}$ in the FG zone (i.e. bottom of the plate in Fig. 1), with equiaxed grains and about $2.5 \mathrm{~mm}$ in the $\mathrm{CG}$ zone (i.e. top of the plate in Fig. 1), with a very serrated grain boundaries (Fig. 3a). The average sizes of the Hf-rich carbides and of $\gamma^{\prime}$ precipitates in the fully heat-treated state were measured to be about $5 \mu \mathrm{m}$ and between 350 and $400 \mathrm{~nm}$, respectively (see Figs. 3c and 3d for typical carbides and $\gamma / \gamma^{\prime}$ microstructures in the alloy, respectively). According to EBSD characterizations, the scatter around a $<001>$ crystallographic orientation was found to be more pronounced in the FG area of the plate compared to the CG one. Pseudo-rocking curves presented in Figure 4 clearly show that grains oriented up to $20^{\circ}$ away from the perfect $<001>$ crystallographic orientation can be found in the FG area (Fig. 4a) while a maximum misorientation of up to $10^{\circ}$ from the $<001>$ direction is observed in the CG area (Fig. 4b).

To characterize the microstructure evolutions of DS200+Hf after mechanical tests, longitudinal cuts were performed and the samples were mechanically polished up to a mirror finish. To reveal the $\gamma / \gamma^{\prime}-$ microstructure, specimens were etched in a solution made of $1 / 3$ $\mathrm{HNO}_{3}$ and $2 / 3 \mathrm{HCl}$ (vol. pct.) for 10 seconds. This chemical attack selectively dissolves the $\gamma^{\prime}$-phase. This preparation allows both the characterization of the grain structure and of the different classes of precipitates (carbides, $\gamma^{\prime}$ phase and $\gamma$ phase) by scanning electron microscopy (SEM). $\gamma / \gamma^{\prime}$ microstructure and fracture surface observations were performed using a JEOL JSM ${ }^{\mathrm{TM}} 7000 \mathrm{~F}$ field emission gun SEM and a JEOL JSM ${ }^{\mathrm{TM}}$ 6400F SEM respectively. Both secondary and backscattered electron imaging modes were used. Observations were performed using an acceleration voltage of $25 \mathrm{kV}$.

\section{$\underline{\text { Environmental resistance characterization }}$}

Isothermal oxidation tests were performed using a SETARAM SETSYS Evolution 16/18 thermobalance. Thanks to its symmetrical furnace arrangement, this thermobalance offers an excellent accuracy (of $\sim 0.002 \mu \mathrm{g}$ ) with limited drift and buoyancy effects. Experiments were performed for 100 hours at $900{ }^{\circ} \mathrm{C}+/$ $0.2{ }^{\circ} \mathrm{C}$, in synthetic air (i.e. without humidity and other impurities). 


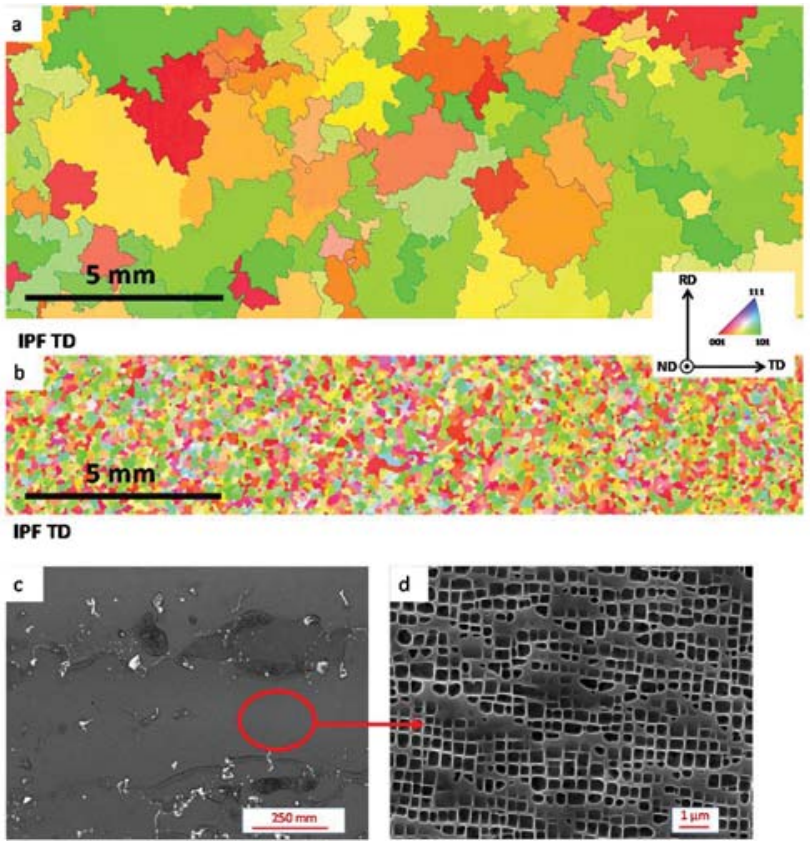

Figure 3. EBSD characterization in a plane perpendicular to the solidification direction (a) in the CG area and (b) in the FG area; microstructure at the (c) dendritic scale with Hf-rich carbides and eutectics and at the (d) $\gamma / \gamma^{\prime}$ precipitation scale. Note that color code used in (a) and (b) refers to crystallographic orientation along the TD direction (horizontal axis).

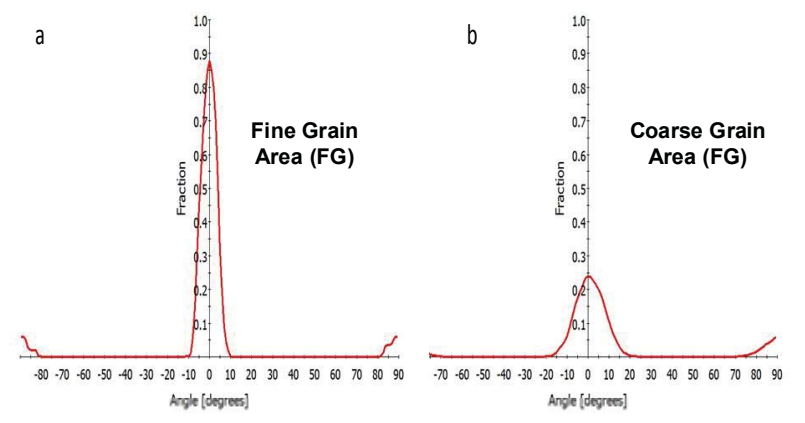

Figure 4. Pseudo-rocking curves around the $<001>$ crystallographic direction in (a) the FG area and (b) CG area.

\section{Mechanical testing}

To investigate the anisotropy in creep properties of DS200+Hf alloy, creep tests were conducted at $750{ }^{\circ} \mathrm{C} / 800 \mathrm{MPa}$, $900{ }^{\circ} \mathrm{C} / 250 \mathrm{MPa}, 900{ }^{\circ} \mathrm{C} / 300 \mathrm{MPa}, 900{ }^{\circ} \mathrm{C} / 350 \mathrm{MPa}$, $900{ }^{\circ} \mathrm{C} / 400 \mathrm{MPa}$ and $1100{ }^{\circ} \mathrm{C} / 70 \mathrm{MPa}$. For some of these conditions $\left(900{ }^{\circ} \mathrm{C} / 350\right.$ and $\left.400 \mathrm{MPa}\right)$, interrupted tests were performed up to 0.8 and $2 \%$ creep strains. These tests were performed in a creep machine equipped with a laser extensometer. Heating was ensured with a radiant furnace. Temperature was controlled using a S-type thermocouple which was attached to the specimen with $\mathrm{a}+/-2^{\circ} \mathrm{C}$ accuracy. A constant load was applied during the experiment. The interested reader is referred to [17] for additional details. In situ monitoring of creep strain heterogeneities were performed using $1.5 \mathrm{~mm}$ thick specimens machined from cylindrical specimens by EDM. Specifically developed ceramic markers were placed in each different grain in order to measure local displacement by videoextensometry. Before placing these markers, an EBSD map was done to be able to localize grain boundaries. During creep test, the barycenter of the markers was filmed through a slot in the radiant furnace with a high resolution camera. Pictures were then filtered using a bespoke software that calculates the displacement between two different markers.

Additional creep tests under high vacuum (pressure below $8.010^{-7}$ mbar) were performed using a computer controlled servohydraulic Instron 1271 testing system. Heating was also ensured with a radiant furnace. These experiments were carried at $900{ }^{\circ} \mathrm{C}$ under initially applied stresses of $350 \mathrm{MPa}$ and $400 \mathrm{MPa}$. "Combo" creep tests were also performed in this work at $900{ }^{\circ} \mathrm{C} / 350 \mathrm{MPa}$. These tests consist of starting the experiment in air up to a $0.8 \%$ creep strain, and then continuing it under vacuum up to failure, using the above-mentioned creep rig.

The thin-wall debit in creep properties was investigated at $900{ }^{\circ} \mathrm{C}$ $+/-1^{\circ} \mathrm{C}$, with an initial applied stress of $350 \mathrm{MPa}$, using a resistive furnace. Before applying the mechanical load, a three hours soak time has been used.

\section{Results}

\section{TGA experiments}

Figure 5 shows the TGA results in air at $900{ }^{\circ} \mathrm{C}$. Compared to the reference single-crystal specimen, it is observed a slightly higher mass gain for T-FG and T-CG samples. The specific weight change is indeed $\sim 20 \%$ greater in the T-FG sample compared to the SX one at the end of the experiments. Moreover, it is observed that this mass gain is slightly higher in the T-FG sample compared to the T$\mathrm{CG}$ one. This is clear indication that grain boundaries act as easier paths for element diffusion, resulting in faster oxidation. Top view observations of the samples after these oxidation tests (not shown here) also evidenced such a preferred grain boundary oxidation.

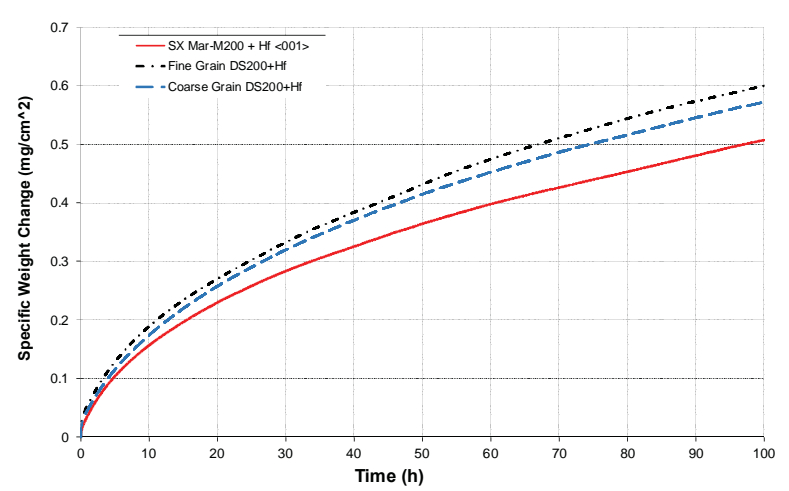

Figure 5. Specific weight evolutions at $900{ }^{\circ} \mathrm{C}$.

\section{Creep behavior and life}

Most of the creep tests were performed at $900{ }^{\circ} \mathrm{C}$. Figure 6 shows the creep behavior at $900{ }^{\circ} \mathrm{C} / 350 \mathrm{MPa}$ under air or vacuum for all type of samples (i.e. $<001>$ SX, T-FG, T-CG and L samples). As observed in Fig. 6b, two stages of creep deformation are observed, whatever the sample type and environment (note that SX curves have been removed in Fig. $6 \mathrm{~b}$ to lighten this plot). Indeed, after a limited primary creep stage (between 0.5 and $1 \%$ in creep strain amplitude) a continuous strain rate increase (i.e. tertiary creep stage) is observed. No clear secondary creep stage can be 
distinguished in these curves. It is also observed in Fig. $6 \mathrm{~b}$ that the minimum creep rate is hardly affected by the loading direction, especially under vacuum. According to Reed \& al. [18], such a tertiary dominated creep behavior in Ni-based SX in this temperature range is typical of a progressive $\gamma^{\prime}$ coarsening, leading to a continuous creep strain acceleration. Microstructure observations presented later in this paper will confirm such a microstructure evolution. A significant decrease of the strain to failure is observed for samples loaded along the transverse direction compared to samples tested along the longitudinal direction or to $<001>$ SX samples (see Fig. 5a). This lower ductility contributes, at least partly, to the lower creep life for T-type samples. To better understand the creep behavior and the fracture mode under transverse loading, interrupted creep tests were performed in air under $350 \mathrm{MPa}$ and $400 \mathrm{MPa}$ applied stresses. In these tests, the very first intergranular crack initiation stages were observed after a $0.8 \%$ creep, i.e. at the primary/tertiary creep stage transition.

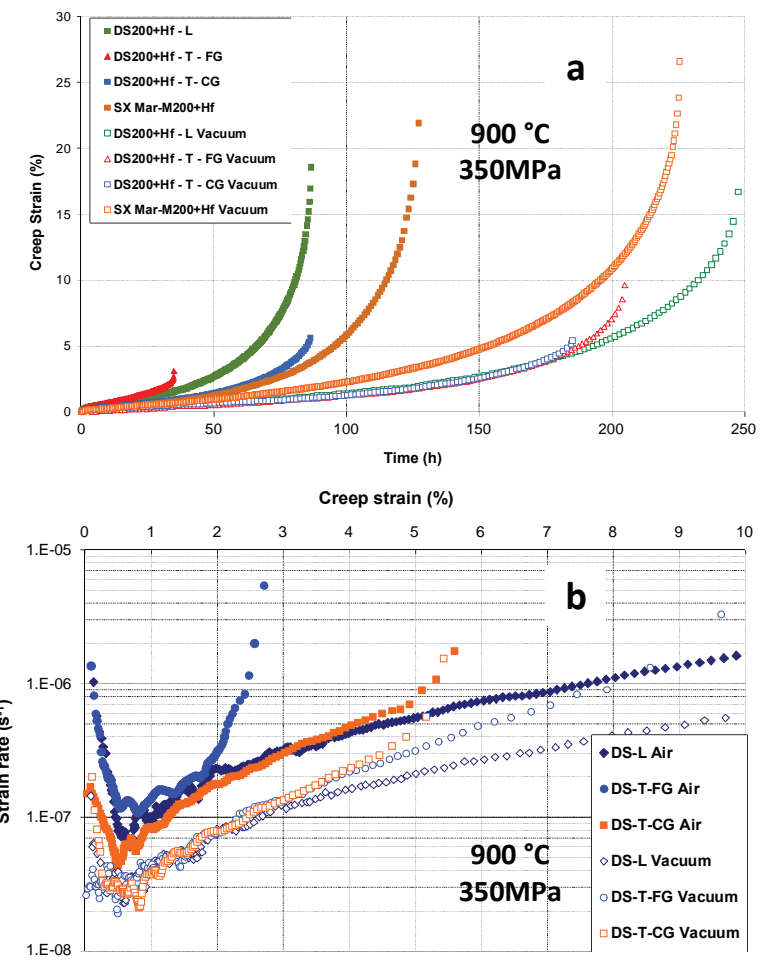

Figure 6. Anisotropy of creep behavior of DS200+Hf alloy at $900{ }^{\circ} \mathrm{C} / 350 \mathrm{MPa}$ in air and under vacuum: (a) Creep strain versus time and (b) Creep strain rate versus creep strain.

Also observed in Figure 6 is the creep life improvement of up to a factor of 5 under vacuum compared to testing under air. Both minimum creep rate and tertiary stages are affected by the environment. Moreover, it is shown in Figure 5 that the grain size effect observed under air when testing along transverse direction disappears under vacuum, suggesting that the difference in creep life and strain rate observed under air (Fig. 6b) is only a result of grain boundary oxidation. Combo creep tests started under air and then continued under vacuum also show this difference in creep strain rate when changing the environment for transverse loading (Fig. 7). It is here recalled that the transition from air to vacuum in these tests was performed after a $0.8 \%$ creep strain, i.e. after the grain boundary crack initiation stage. The minimum creep rate dependence at $900{ }^{\circ} \mathrm{C}$ to the environment hence seems to be mainly correlated to the action of oxidation.

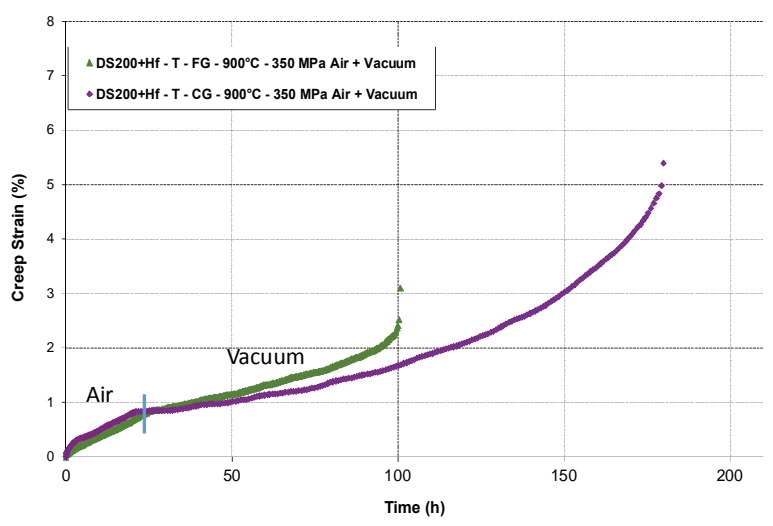

Figure 7. Creep behavior of DS200+Hf alloy at $900{ }^{\circ} \mathrm{C} / 350 \mathrm{MPa}$ in air until $0.8 \%$ of creep strain and then continued under vacuum up to failure.

To further confirm the effect of oxidation on the creep behavior of DS200+Hf alloy, thin-wall creep experiments have been performed at $900{ }^{\circ} \mathrm{C} / 350 \mathrm{MPa}$. Figure 8 shows the evolution of the relative creep life as a function of the $\mathrm{P} / \mathrm{S}$ ratio (perimeter of the gage section over load bearing section ratio). A $\mathrm{P} / \mathrm{S}$ ratio of 1.0 in this plot corresponds to the creep life of the massive sample (sample having a gauge diameter of $4 \mathrm{~mm}$ ), which is taken as the reference. It has been chosen to use such a $\mathrm{P} / \mathrm{S}$ parameter to analyze the thin wall debit in creep life since all our specimens do not have the same geometry and since it is a reliable factor to measure the external surface of specimens exposed to oxidation relatively to their load bearing section. Indeed, a high $\mathrm{P} / \mathrm{S}$ ratio corresponds to a specimen in which the surface exposed to oxidation is large in comparison to its load bearing section, while a small $\mathrm{P} / \mathrm{S}$ ratio corresponds to a massive sample in which oxidation is expected to have little influence.

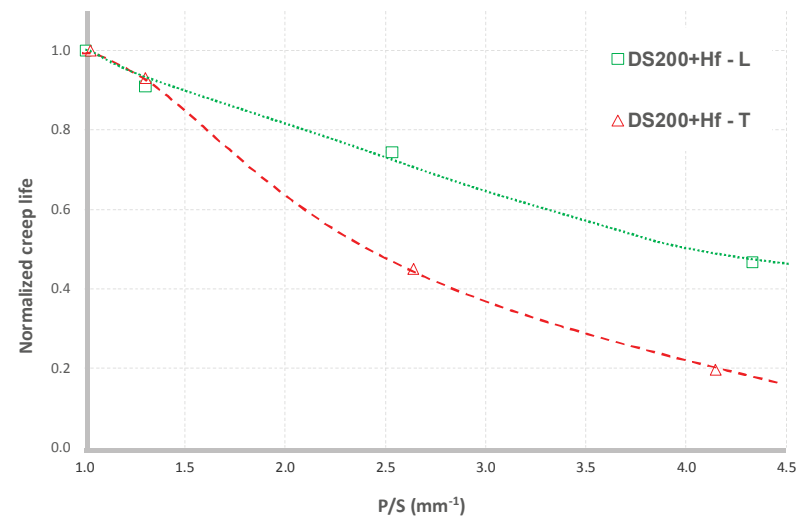

Figure 8. Thickness debit in creep life at $900{ }^{\circ} \mathrm{C} / 350 \mathrm{MPa}$. Note the each creep life has been normalized by the creep life of the massive specimen having a $4 \mathrm{~mm}$ gage diameter $(\mathrm{a} / \mathrm{S}$ ratio of $\sim 1$ ).

A progressive decrease of the creep life is observed in Fig. 8 with thinner specimens in both loading directions. This thin-wall creep debit is more pronounced for transverse samples (up to a factor of 
5 for transverse loading compared to a factor of $\sim 2$ for longitudinal loading), as expected considering grain boundaries oxidation. A decrease in ductility has also been observed for both types of specimen decreasing the thickness. It has to be noted that, even if it is not observed in this normalized representation, T-type specimens always exhibited lower creep lives compared to L-type ones, whatever the sample thickness. The thin-wall creep debit observed in these experiments is in good agreement with other results obtained using single crystalline superalloys [19-22]. However, despite a schematic illustration of the thickness debit evolution in creep for columnar grain and conventionally cast superalloys as has been proposed by Seetharaman and Cetel [20], we believe that the data presented in this paper are the first ones available for DS superalloys in the open literature.

Additional creep tests were also performed at $750{ }^{\circ} \mathrm{C} / 800 \mathrm{MPa}$ and $1100{ }^{\circ} \mathrm{C} / 70 \mathrm{MPa}$ (Fig. 9). These conditions were chosen to respectively reduce or enhance the contribution of oxidation to the creep damage mechanism and also to favor $\gamma^{\prime}$ rafting for this second condition. The creep curves at $750^{\circ} \mathrm{C} / 800 \mathrm{MPa}$ exhibit the classical three stages of creep deformation, with a large primary creep strain amplitude of up to $3-4 \%$ along longitudinal direction or for the $<001>$ SX specimens. Under this creep condition, T-type samples fail during the primary creep stage due to their intrinsic lack of high temperature ductility (see insert in Fig. 9a). At $1100{ }^{\circ} \mathrm{C}$, the creep behavior consists in a fast primary creep stage, followed by a slow secondary creep stage and a steep tertiary creep stage. Such a creep behavior is typical of the $\gamma^{\prime}$-rafting regime, the end of the primary creep stage being linked to the kinetics of $\gamma^{\prime}$-rafting completion and the stage II strain rate to the stability of the $\gamma / \gamma^{\prime}$ lamellar structure [18]. It is also observed that the creep life anisotropy at this temperature is greatly reduced, probably due to a prominent contribution of oxidation in controlling the occurrence of the tertiary creep stage. All these results confirm that the anisotropy in creep life increases when temperature decreases: creep life along the transverse direction is nearly 80 to 100 times smaller than for single crystal at $750{ }^{\circ} \mathrm{C}$, while this factor is of nearly 2 at $1100{ }^{\circ} \mathrm{C}$. Such a result is highlighted in the Larson-Miller plot presented in Figure 10 that shows a larger difference in creep life at high applied stresses (i.e. low temperature) in comparison to high temperature testing conditions.

In order to better understand DS200+Hf anisotropy in creep properties, several creep experiments were also performed at $750{ }^{\circ} \mathrm{C} / 800 \mathrm{MPa}$ (Fig. 9a) and at $900{ }^{\circ} \mathrm{C} / 300 \mathrm{MPa}$ (Fig. 11) using single crystalline samples far away from the perfect $<001>$ crystallographic orientation. If primary and secondary misorientations of $\sim 25^{\circ}$ and $8.5^{\circ}$ respectively have a limited influence on the creep behavior and life in these two creep testing conditions, large primary and secondary misorientations of $46^{\circ}$ and $20^{\circ}$ have a huge impact on the creep properties, especially at $750{ }^{\circ} \mathrm{C} / 800 \mathrm{MPa}$, where no strain hardening is observed in the creep behavior. After a short incubation period of nearly 2 minutes, these highly misoriented samples failed in less than 30 minutes (blue curve at the extreme left in Fig. 9a). These results are in good agreement with the well-known anisotropy in creep life at low temperature and high applied stress [23-25].
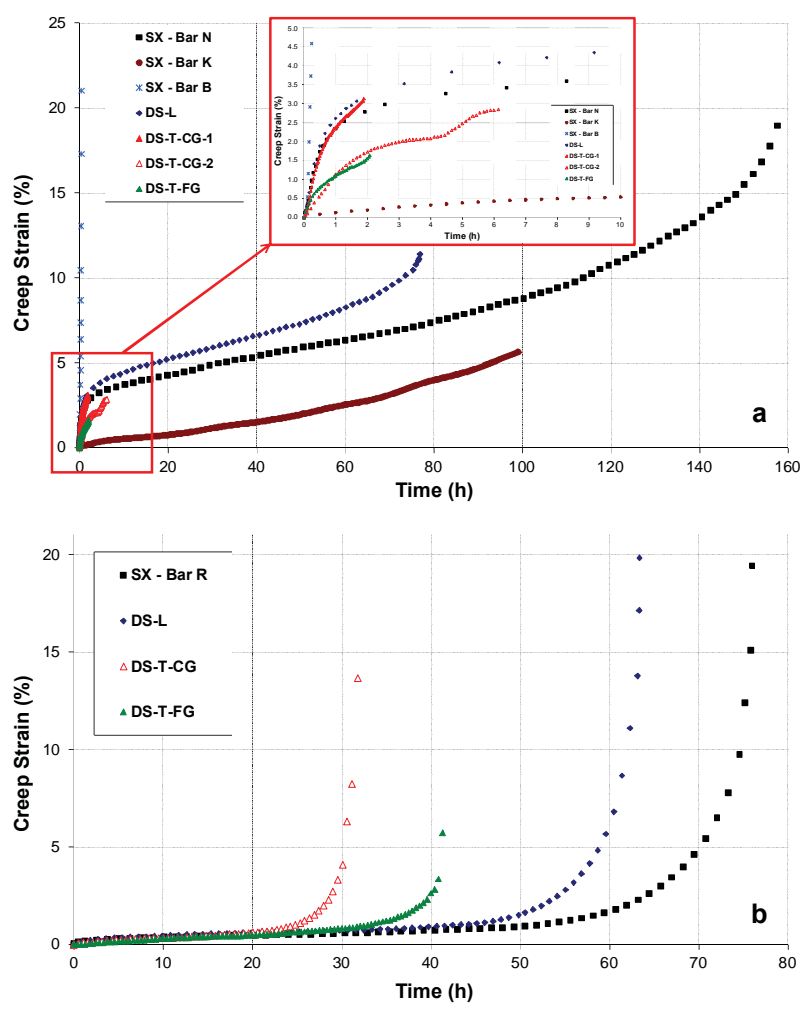

Figure 9. Creep behavior anisotropy of DS200+Hf and SX MarM200+Hf alloys at $750{ }^{\circ} \mathrm{C} / 800 \mathrm{MPa}$ (a) and at $1100{ }^{\circ} \mathrm{C} / 70 \mathrm{MPa}$ (b).

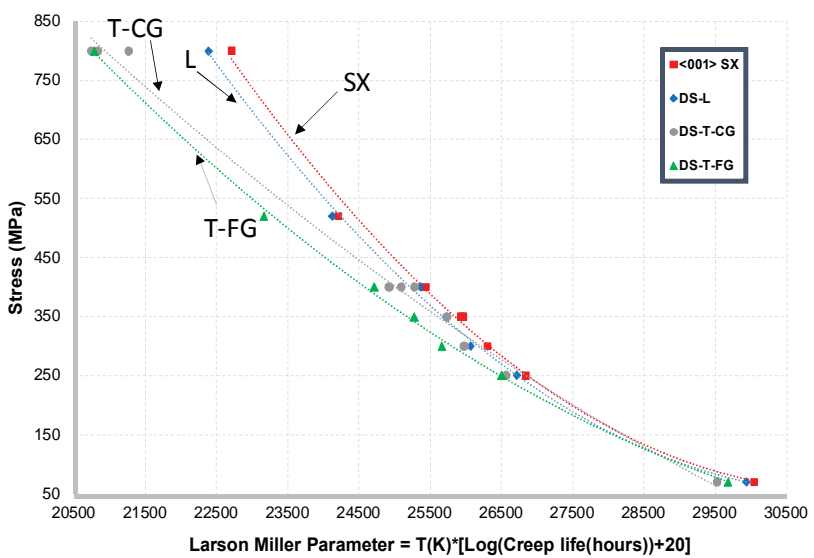

Figure 10. Larson-Miller plot for DS200+Hf (along longitudinal and transverse directions) compared to the creep resistance of SX Mar-M200+Hf along the $<001>$ direction. 


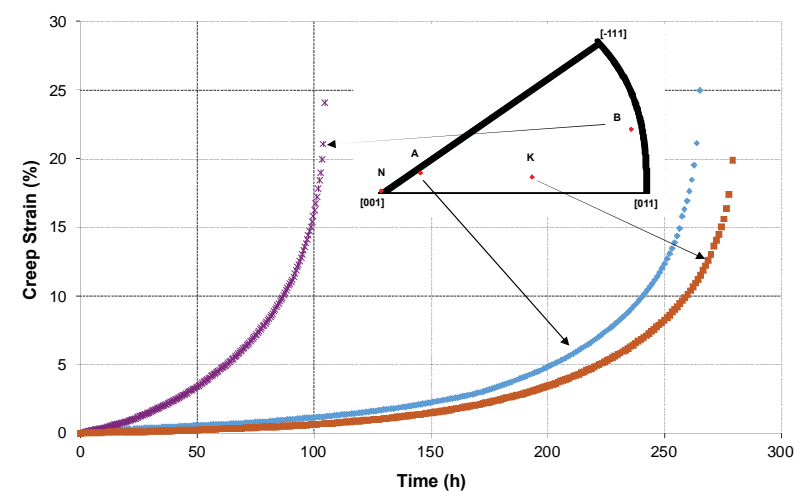

Figure 11. Creep behavior anisotropy of SX Mar-M200+Hf alloy at $900{ }^{\circ} \mathrm{C} / 300 \mathrm{MPa}$.

\section{$\underline{\text { In situ monitoring of creep strain heterogeneities }}$}

In situ monitoring of creep strain heterogeneities was performed at $750{ }^{\circ} \mathrm{C} / 800 \mathrm{MPa}$ (Fig. 12a) and $900{ }^{\circ} \mathrm{C} / 400 \mathrm{MPa}$ (Fig. 12b). Before experiments, EBSD characterizations of the gage surfaces were performed to be able to localize each grain boundary and the local orientation with respect to the loading axis. The solidification direction is vertical in the EBSD maps shown in Fig. 12 (i.e. perpendicular to the stress axis). The creep test performed at $750{ }^{\circ} \mathrm{C} / 800 \mathrm{MPa}$ has especially been chosen to have a limited impact of oxidation on GB crack nucleation and no $\gamma / \gamma^{\prime}$ morphological evolution compared to the test at $900{ }^{\circ} \mathrm{C}$. For both experiments, differences in creep elongation at the grain scale are observed, especially at $750{ }^{\circ} \mathrm{C} / 800 \mathrm{MPa}$ where a factor greater than 2.5 is obtained between the grains having undergone the largest creep strains (grains 1 and 4) and the grain with the lowest plastic deformation (grain 3). At $900^{\circ} \mathrm{C}$, a more homogeneous creep strain field is observed, with a contrast in creep strain at the grain scale lower than 1.5. This creep strain heterogeneity is especially observed during the creep strain acceleration regime, when the $\gamma^{\prime}$ rafting is taking place (see subsequent section), leading to a more homogeneous creep deformation. In both experiments, crack development at grain boundaries was observed (see arrows in Fig. 12). Cracks have been observed to nucleate at grain boundaries separating two grains having a mismatch in creep deformation, but not necessarily the largest one (green arrows in Fig. 11 highlight the mismatches in creep strain between two neighboring grains). However, thanks to EBSD characterizations, it has been observed that cracks first nucleate at GB with a large misorientation between neighboring grains (the so-called high angle boundaries). This is especially the case for the experiment at $750{ }^{\circ} \mathrm{C} / 800 \mathrm{MPa}$ where the crack nucleated between two grains with the largest possible misorientation for such a DS alloy loaded along transverse direction (i.e. a nearly 45 degrees misorientation between the $<100>$ G1 grain and the $\sim<110>$ G2 grain). The situation is less obvious for the experiment performed at $900{ }^{\circ} \mathrm{C} / 400 \mathrm{MPa}$ since no configuration with such high angle boundary was encountered.

According to the locations of crack development at both temperatures, it is intuited by the authors that the contrast in local moduli (i.e. contrast in elastic strain) and the ability for grain rotation will be the critical parameters controlling grain boundary crack initiation. Indeed, almost no contrast in Schmid factor is observed between grain 1 and grain 2 in Fig. 12a (a Schmid factor of $\sim 0.41$ is obtained for both grains) and the situation is similar at $900{ }^{\circ} \mathrm{C} / 400 \mathrm{MPa}$ where the Schmid factors have been superimposed to the EBSD map. In each experiment, the Schmid factors of the four most heavily loaded slip systems have been calculated and no correlation could have been identified between the crack nucleation sites and the local plastic activity. It is also observed at $750{ }^{\circ} \mathrm{C} / 800 \mathrm{MPa}$ that the grain G2 has a very low creep rate all along the experiment, except at the very end of the test, after the main crack had nucleated. The creep behavior of this grain which has a near $<110>$ orientation with respect to the stress axis should have exhibited a very low creep resistance according to the experiment performed using a single crystalline sample with a similar orientation (test on B bar, see insert in Fig. 9a, blue dotted curve at the very left) and to literature [23, 24]. We here suspect that the immediate neighbors of grain $\mathrm{G} 2$ in this experiment are imposing boundary conditions preventing grain G2 from rotating, as this is observed for such an orientation under these creep conditions [23, 24, 26, 27]. Once the crack is nucleated, this grain can rotate and it is observed in Fig. 11a a creep acceleration, while in other grains (i.e. grains G1, G4 and G3 to a lower extent), a decrease of the strain is observed, due to an apparent decrease of the elastic stiffness of the sample after crack nucleation. At $900^{\circ} \mathrm{C}$, these mechanisms are more difficult to observe due to both the $\gamma / \gamma^{\prime}$ morphological evolution and the action of oxidation which is believed to have a prominent contribution to the crack propagation stage, according to the creep results shown in the previous sections and microstructure observations presented in a following section.

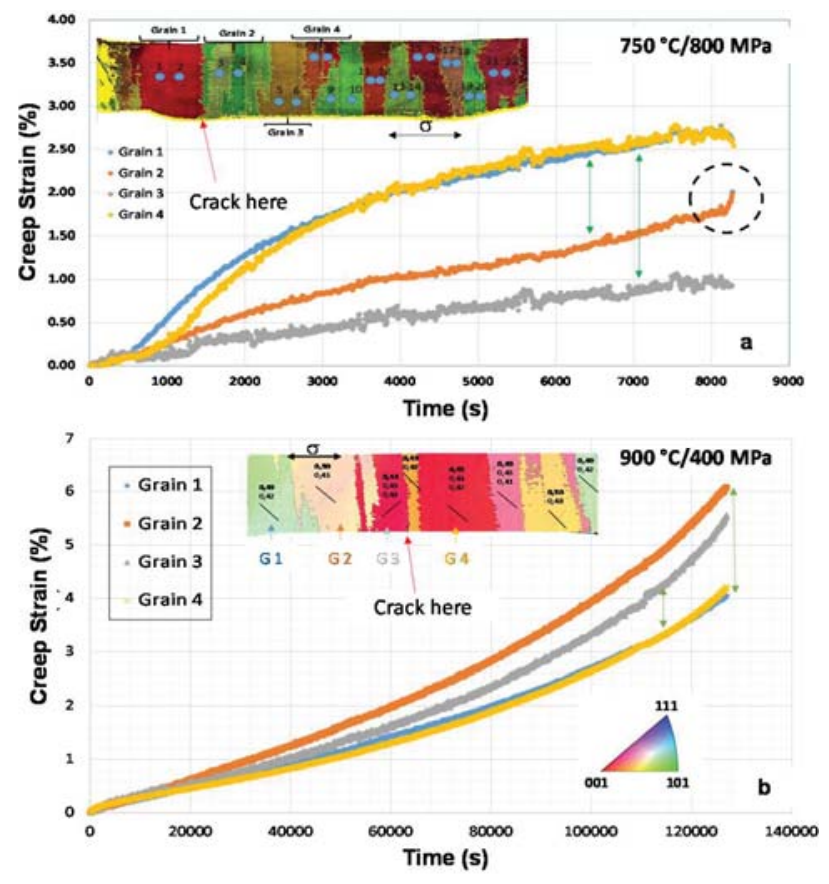

Figure 12. Creep strain heterogeneity during transverse loading, at $750{ }^{\circ} \mathrm{C} / 800 \mathrm{MPa}(\mathrm{a})$ and $900{ }^{\circ} \mathrm{C} / 400 \mathrm{MPa}(\mathrm{b})$. Note that the color code used in the EBSD maps of the gauge surfaces presented in this figure refers to the loading axis. The grains in which creep strain evolutions are presented have been identified on each EBSD map (grains G1, G2, G3 and G4). The dotted circle in (a) highlight the creep acceleration once the main crack has been developed. 
Bulk Microstructure observations

During creep tests performed at $900{ }^{\circ} \mathrm{C}$ and $1100^{\circ} \mathrm{C}$, the $\gamma^{\prime}$-rafting phenomenon is observed, whatever the testing direction (see Fig. 13). Figures $13 \mathrm{~b}$ and $13 \mathrm{c}$ compare the difference in $\gamma^{\prime}$ directional coarsening at $900{ }^{\circ} \mathrm{C} / 250 \mathrm{MPa}$, and $900{ }^{\circ} \mathrm{C} / 400 \mathrm{MPa}$. A more developed $\gamma^{\prime}$ rafting is observed after failure at $900{ }^{\circ} \mathrm{C} / 250 \mathrm{MPa}$ due to a longer time at high temperature. In Fig. 13b, $\gamma^{\prime}$-rafting is clearly under progress, with some remaining $\gamma$-particles trapped inside $\gamma^{\prime}$ precipitates, in agreement with Reed et al. [28]. Since $\gamma^{\prime}$ rafting was already observed in the rhenium containing CMSX-4 alloy at temperature greater than $850{ }^{\circ} \mathrm{C}$ by Epishin et al. [29], this is not a surprise to observe this microstructure degeneration at this relatively low temperature. At $750{ }^{\circ} \mathrm{C} / 800 \mathrm{MPa}$, no evidence of $\gamma^{\prime}$ morphological evolution has been noticed (see Fig. 13a), despite large creep strains at failure for single crystalline and L-type samples. The main difference in $\gamma / \gamma^{\prime}$ morphological evolution for tests under transverse direction is that the $\gamma^{\prime}$-rafting process depends on the grain orientation, and not directly on the direction of the applied stress (see e.g. Fig. 15). Such an observation is in good agreement with recent compression creep experiments performed using the polycrystalline Inconel 738LC alloy [30].

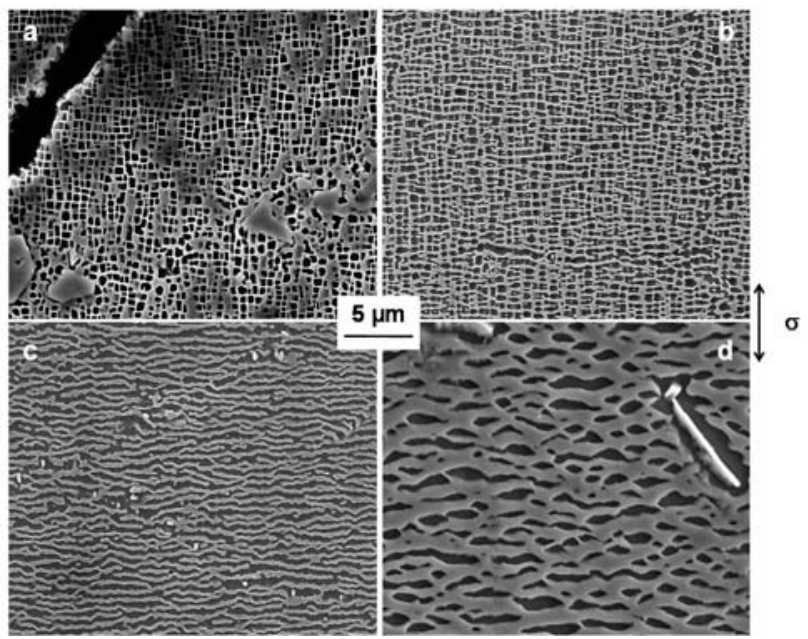

Figure 13. $\gamma / \gamma^{\prime}$ microstructure after creep tests up to failure performed at (a) $750{ }^{\circ} \mathrm{C} / 800 \mathrm{MPa}$, (b) $900{ }^{\circ} \mathrm{C} / 400 \mathrm{MPa}$, (c) 900 ${ }^{\circ} \mathrm{C} / 250 \mathrm{MPa}$ and (d) $1100{ }^{\circ} \mathrm{C} / 70 \mathrm{MPa}$ (L type specimens).

\section{$\underline{\text { Failure mechanisms characterizations }}$}

Fracture surface observations revealed an intergranular failure mode for the DS specimen loaded along the transverse direction, with a fracture surface aspect in good agreement with a recent study using GTD 444 and René N4 bicrystalline samples [27]. As observed in Fig. 14 for a FG sample tested under combo (vacuum + air) conditions (see Fig. 7), strips all oriented in the same direction on the fracture surface are typical of the intergranular failure of T-type samples. These features correspond to the grain boundary tortuosity resulting from the intragranular dendritic structure and they are oriented along the solidification direction. A careful observation of combo creep test also clearly show that small cracks had started to develop under air and then crack propagation continued under vacuum. The very first stages of crack propagation are indeed highlighted in Fig. 14 by a red dotted line, where an oxidized crack propagation area is observed on the fracture surface.
This result is in good agreement with the identification of a creep strain threshold of $\sim 0.8 \%$ for intergranular crack initiation using several interrupted creep tests in air.

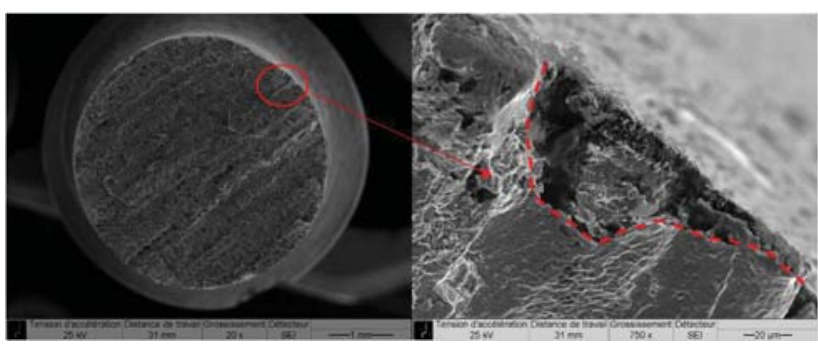

Figure 14. Fracture surface of DS200+Hf after combo creep testing at $900{ }^{\circ} \mathrm{C} / 350 \mathrm{MPa}$ in air until $0.8 \%$ of creep strain and then under vacuum up to failure. (T: Transverse testing, FG: Fine Grains).

SEM observations along longitudinal cuts show more clearly that cracks follow grain boundaries during transverse loading, whatever the environment (see Fig. 15 and 16). This crack propagation mode is in good agreement with [31]. It is also clearly observed that the crack propagation is assisted by oxidation since a $\gamma^{\prime}$ depleted layer is observed close to the crack propagation path in all the observed configurations under air (see Fig. $15 \mathrm{~b}$ and $15 \mathrm{~d}$ taken using the electron backscattered imaging mode). This $\gamma^{\prime}$ depleted layer is, however, absent during tests under vacuum (Fig. 16b). Another type of damage at grain boundary has been observed after creep tests. Indeed, cavitation and small cracks without any action of oxidation have been detected both in T-type specimens (see e.g. Fig. $15 \mathrm{c}$ ) but also for L-type samples at $750{ }^{\circ} \mathrm{C} / 800^{\circ} \mathrm{C}$ (see upper left corner of Fig. 13a). Such a crack initiation process under longitudinal testing agrees well with a recent publication from Tian et al. [32]. It is shown in their paper that in the later stages of creep along the longitudinal direction in a similar DS alloy, and at a temperature close to $780^{\circ} \mathrm{C}$, the cracks first initiate and propagate along grain boundary oriented at about $45^{\circ}$ relative to the stress axis. These grain boundary bear the bigger shear stress during creep, which is responsible for the crack initiation at such a specific portion of grain boundaries. The subsequent long crack propagation stage for L-type samples is transgranular and almost perpendicular to the applied stress axis. In summary, this second type of intergranular damage mechanisms along $\mathrm{L}$ and $\mathrm{T}$ type sample may be classified as creep-strain induced grain boundary damage.

It is observed in Fig. 17 that nearly all the carbides connected to the surface exhibit a volumetric expansion at the surface and most of them have been cracked by the $3 \mathrm{~h}$ pure thermal exposure (see Fig. 17a). A similar observation was done after 5 minutes of thermal exposure at $900{ }^{\circ} \mathrm{C}$ with a lower fraction of fractured carbides. Moreover, in some places after $3 \mathrm{~h}$ of oxidation at $900{ }^{\circ} \mathrm{C}$, the very first evidence of cracks has been observed (see arrows in Fig. 17b). These cracks have been observed close to a eutectic where oxide scale spallation occurred. Taking into account these surface observations after pure thermal exposure in air, it is believed that the fatigue life at $900{ }^{\circ} \mathrm{C}$ is mainly crack propagation controlled, since many carbides are already cracked at the beginning of the mechanical loading during fatigue tests and they act as crack initiation sites. 

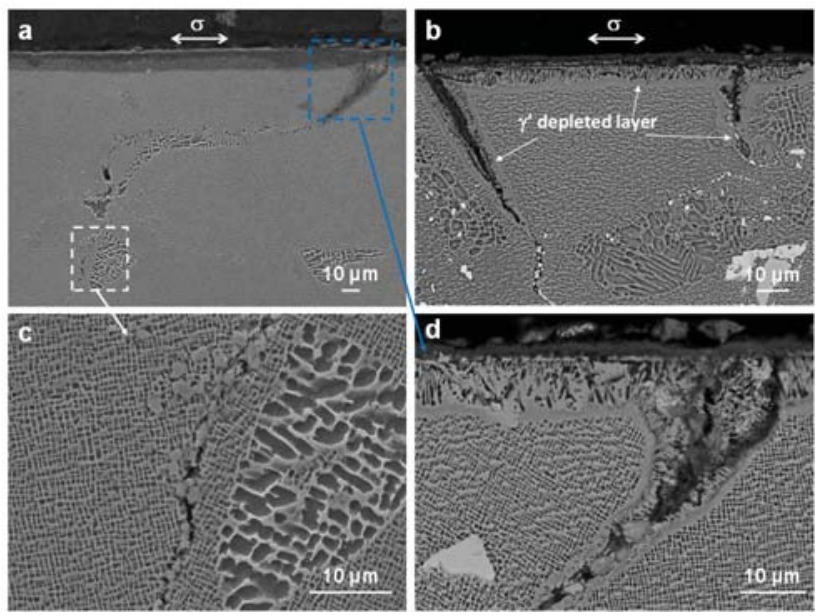

Figure 15. Creep damage mechanisms after 62 hours in creep at $900{ }^{\circ} \mathrm{C} / 350 \mathrm{MPa}$ (Creep strain $=3.8 \%$ ) along transverse direction in a $0.8 \mathrm{~mm}$ thick sample (a, b). (c) and (d) are magnified areas of (a) showing bulk GB cavitation (c) and oxidation assisted GB cracking (d). (b) is another area of the specimen showing oxidation assisted GB cracks.
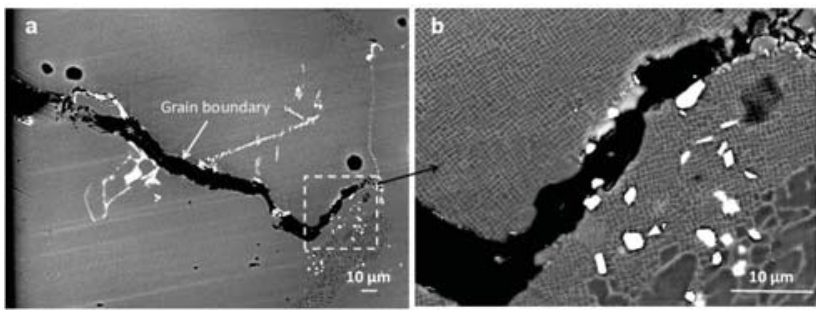

Figure 16. GB crack propagation in a FG DS200+Hf specimen tested along transverse direction at $900{ }^{\circ} \mathrm{C} / 350 \mathrm{MPa}$ in vacuum (a) showing no $\gamma^{\prime}$ depleted layer close to the crack path (b).
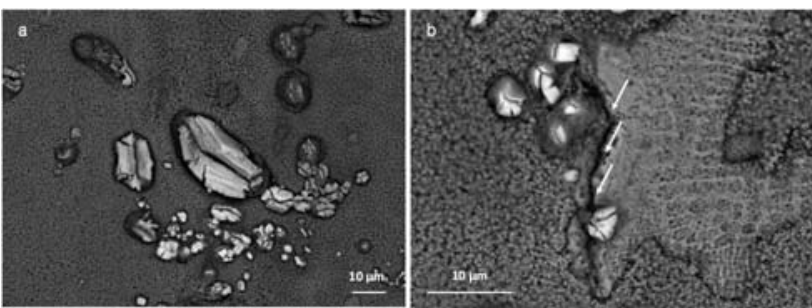

Figure 17. Surface DS200+Hf specimens after 3 hours of pure thermal exposure at $900{ }^{\circ} \mathrm{C}$ in air showing fractured carbides (a) and first stages of crack development close to a eutectic (see white arrows) (b). Note that observation in (b) has been performed using the BSE imaging mode.

\section{Discussion}

This paper shows that the anisotropy in creep life of DS200+Hf is highly temperature dependent (Figs. 6 and 9). The anisotropy in creep life decreases with a temperature increase. This is in good agreement with the general trend observed in Ni-based single crystalline superalloys [23-25]. However, little work has been done up to now on the factors affecting the anisotropy in creep properties of DS alloys, and, especially, the contribution of oxidation to the damage mechanisms.

The main factor contributing to the creep anisotropy of DS200+Hf alloy is the change in fracture mode, which is intergranular for transverse loading while it is (mainly) transgranular for DS-L and SX specimens. A part of the lower creep properties along transverse direction results from the lower ductility at high temperature due to this change in fracture mode. Although oxidation has been observed to favor grain boundary crack initiation and subsequent propagation, it is observed that the largest variation is creep life is obtained at $750{ }^{\circ} \mathrm{C}$, where the impact of oxidation on the damage processes can be ruled out. At this temperature, the anisotropy in creep life mainly results from the differences in creep behavior at the grain scale (differences in creep strain rate), as well as the differences in local elastic strain and ability for grain rotation, as proposed by Stinville et al. [27] (see Fig. 12a). Indeed, during transverse creep testing, since crack nucleation is intergranular, the stress state at grain boundaries is critical in controlling crack initiation and this stress state is highly dependent on both the grain boundary morphology and on each grain elasticity. Increasing the temperature to $900{ }^{\circ} \mathrm{C}$ and above leads to a more homogeneous creep deformation at the grain scale (see Fig. 12b) due to the degradation of the $\gamma / \gamma^{\prime}$ microstructure (see Fig. 13b and 13c). However, the anisotropy in creep life is still pronounced at $900{ }^{\circ} \mathrm{C}$ due to the impact of oxidation on the grain boundary crack initiation and propagation, as observed in Figs. 14 and 15. Combo creep tests (Fig. 7) and the greater thickness creep debit along transverse directions (Fig. 8) are clear evidence that oxidation primarily affects at the grain boundary crack propagation stage, probably right from the beginning of the creep tests since surface carbides are already fractured after the soak time at $900{ }^{\circ} \mathrm{C}$ (Fig. 17). Moreover, according to TGA experiments (Fig. 5), grain boundaries have been shown to favor oxidation compared to bulk oxidation and we strongly suspect that Hf-rich carbides and the remaining hafnium atoms in solution segregated at grain boundaries to favor the oxidation sensitivity of the alloy. Although hafnium has been shown necessary in this alloy to increase the high temperature transverse ductility [6], it is also known that this element has a very high affinity with oxygen $[33,34]$. Hence, the high hafnium content of this alloy $(\sim 1.6 \mathrm{wt} \%$, see Table II) is probably too high from an environmental resistance point of view.

\section{Conclusions}

The creep durability at high temperature of DS200+Hf alloy has been investigated along longitudinal and transverse directions and compared to references observed using single crystalline MarM200+Hf specimens. According to this work, the following main conclusions can be established:

- Lower creep and fatigue lives are systematically observed along transverse direction loading axis.

- The lower creep life within all the temperature range and the lower fatigue life at $900{ }^{\circ} \mathrm{C}$ along transverse direction results from a lower high temperature ductility, due to an intergranular failure mode.

- The anisotropy in creep life increases when temperature decreases: creep life along the transverse direction is nearly 80 to 100 times smaller than for $<001>\mathrm{SX}$ specimens at $750^{\circ} \mathrm{C}$, while this factor is of $\sim 2$ at $1100{ }^{\circ} \mathrm{C}$. This variation in creep life anisotropy results from a prominent role of oxidation at very high temperature, combined with the $\gamma^{\prime}$-rafting, and a major contribution of crystallography at low temperatures. 
- $\quad$ The grain size effect observed at $900{ }^{\circ} \mathrm{C}$ when analyzing the creep resistance along transverse direction results from a lower density of grain boundaries exposed to oxidation. No grain size effect is observed under vacuum along this testing direction.

- Oxidation affects the crack propagation stages through a $\gamma^{\prime}$-depletion process at the crack tip. Oxidation also contributes to a larger thickness debit in creep at $900{ }^{\circ} \mathrm{C}$ along transverse direction due to a faster GB oxidation.

- In situ monitoring of creep strain heterogeneities shows that cracks develop between grains having a large deformation and a pronounced local misorientation (large difference in local elasticity and ability for grain rotation), especially at $750{ }^{\circ} \mathrm{C} / 800 \mathrm{MPa}$

\section{Acknowledgments}

The SAFRAN group is gratefully acknowledged for financial support, for providing the material and for L. Mataveli Suave $\mathrm{PhD}$ thesis grant. E. Drouelle (PhD student at Institut Pprime and SAFRAN CRT) is acknowledged for technical assistance in TGA experiments. D. Ponsen (Materials \& Process Engineer at SAFRAN-Snecma) is gratefully acknowledged for casting DS plates and SX bars. C. Biffi, A. Dolmaire, A. Serrano Muñoz and J. Zamarripa Solano (undergraduate students at ISAE-ENSMA) are acknowledged for the preparation of thin-walled creep tests.

\section{References}

1. M.J. Donachie and S.J. Donachie, Superalloys: a technical guide: ASM international, 2002).

2. M. Gell, D.N. Duhl, and A.F. Giamei. "The development of single crystal superalloy turbine blades", (Paper presented at Superalloys 1980, Seven Springs, PA, USA, 1980), 205-214.

3. R.C. Reed, The Superalloys - Fundamentals and Applications (Cambridge, UK: Cambridge University Press, 2006).

4. A.D. Cetel and D.N. Duhl. "Second generation columnar grain nickel-base superalloy", (Paper presented at Superalloys 1992 , Seven Springs, Champion, PA, USA, 1992), 287-296.

5. F.L. Versnyder and M.E. Shank, "The development of columnar grain and single crystal high temperature materials through directional solidification", Materials Science and Engineering, 6 (1970), 213-247.

6. D.N. Duhl and C.P. Sullivan, "Some effects of hafnium additions on the mechanical properties of a columnar-grained nickel-base superalloy", Journal of Metals, 23 (7) (1971), 38-40.

7. M.-S. Chiou et al., "High temperature creep properties of directionally solidified CM-247LC Ni-based superalloy", Materials Science and Engineering: A, 655 (2016), 237-243.

8. K. Harris, G. Erickson, and R. Schwer, "Directionally solidified and single-crystal superalloys", ASM International, Metals Handbook. Tenth Edition., 1 (1990), 995-1006.
9. J.J. Jackson et al., "The effects of volume percent of fine $\gamma^{\prime}$ on creep in DS Mar-M200 + Hf", Metallurgical Transactions, 8A (October) (1977), 1615-1620.

10. Z. Yunrong et al. "Effect of chemistry modifications and heat treatments on the mechanical properties of DS MAR-M200 superalloy", (Paper presented at Superalloys 1988, Seven Springs, Champion, PA, USA, 1988), 335-344.

11. X. He et al., "Influence of orientation and temperature on the fatigue crack growth of a nickel-based directionally solidified superalloy", Materials Science and Engineering: A, 618 (2014), $153-160$.

12. J. Huang, D. Shi, and X. Yang, "A modern and robust methodology for modeling anisotropic creep characteristics of $\mathrm{Ni}$ based DS and SC superalloys", Science China Technological Sciences, 57 (9) (2014), 1802-1815.

13. M. Shenoy, D. Mcdowell, and R. Neu, "Transversely isotropic viscoplasticity model for a directionally solidified Ni-base superalloy", International journal of plasticity, 22 (12) (2006), $2301-2326$

14. P.K. Wright and A.F. Anderson. "The influence of orientation on the fatigue of directionally solidified superalloys", (Paper presented at Superalloys 1980, Metals Park, OH, 1980), 689-698.

15. K. Harris, G. Erickson, and R. Schwer. "CMSX single crystal, CM DS \& integral wheel alloys properties \& performance", (Paper presented at Cost Conference "High temperature alloys for gas turbines and other applications", Liège, Belgium, 1986), 6-9.

16. P. Caron and T. Khan, "Improvement of creep strenght in a nickel-base single crystal superalloy by heat treatment", Materials Science and Engineering, 61 (1983), 173-194.

17. J. Cormier et al., "Very high temperature creep behavior of a single crystal Ni-based superalloy under complex thermal cycling conditions", Philosophical Magazine Letters, 90 (8) (2010), 611620

18. R.C. Reed et al., "Creep of CMSX-4 superalloy single crystals: effects of rafting at high temperature", Acta mater, 47 (12) (1999), $3367-3381$

19. M. Bensch et al., "Influence of Oxidation on Near-Surface $\gamma^{\prime}$ Fraction and Resulting Creep Behavior of Single Crystal Ni-Base Superalloy M247LC SX", Material Science and Engineering A, 577 (2013), 179-188.

20. V. Seetharaman and A.D. Cetel. "Thickness debit in creep properties of PWA 1484", (Paper presented at Superalloys 2004 Seven Springs, PA, USA, 2004), 207-214.

21. A. Srivastava et al., "Effect of specimen thickness on the creep response of a Ni-based single-crystal superalloy", Acta Materialia, 60 (16) (2012).

22. M. Brunner et al., "Thickness Influence on Creep Properties for Ni-Based Superalloy M247LC SX", Materials Science and Engineering A, 550 (2012), 254-262. 
23. P. Caron et al. "Creep deformation anisotropy in single crystal superalloys", (Paper presented at Superalloys 1988, Seven Springs, Champion, PA, USA, 1988), 215-224.

24. R.A. Mackay and R.D. Maier, "The Influence of Orientation on the Stress Rupture Properties of Nickel-Base Superalloy Single Crystals", Metallurgical and Materials Transactions A, 13A (1982), 1747-1754.

25. V. Sass, U. Glatzel, and M. Feller-Kniepmeier, "Anisotropic creep properties of nickel-base superalloy CMSX-4", Acta mater, 44 (5) (1996), 1967-1977.

26. M.G. Ardakani et al., "Implications of dislocation micromechanisms for changes in orientation and shape of single crystal superalloys", Scripta Materiala, 39 (4-5) (1998), 465-472.

27. J.C. Stinville, K. Gallup, and T.M. Pollock, "Transverse Creep of Nickel-Base Superalloy Bicrystals", Metallurgical and Materials Transactions A, 46A (2015), 2516-2529.

28. R.C. Reed, D.C. Cox, and C.M.F. Rae, "Kinetics of rafting in a single crystal superalloy: effects of residual microsegregation", Materials Science and Technology, 23 (8) (2007), 893-902.

29. A. Epishin et al., "Creep damage of single-crystal superalloys: mechanisms and effect on low cyle fatigue", Materials At High Temperarture, 23 (1) (2010), 53-59.

30. A. Altincekiç and E. Balikçi, "Precipitate Rafting in a Polycrystalline Superalloy During Compression Creep", Metallurgical and Materials Transactions A, 45A (2014), 59235936.

31. S. Tian et al., "Influence of solution temperature on microstructure and creep property of a directional solidified nickelbased superalloy at intermediate temperatures", Materials Science and Engineering A, 615 (2014), 469-480.

32. Q. Li et al., "Effects of carbides and its evolution on creep properties of a directionally solidified nickel-based superalloy", Materials Science and Engineering A, 633 (2015), 20-27.

33. F.S. Pettit and G.H. Meier. "Oxidation and Hot Corrosion of Superalloys", (Paper presented at Superalloys 1984, Seven Springs, Champion, PA, USA, 1984), 651-687.

34. W.H. Sutton and D.R. Green. "Influence of Hf on the Wetting Characteristics of MAR M-200", (Paper presented at Superalloys, Metallurgy and Manufacture, 1976), 171-179. 